\title{
Supported Tetrahedral Oxo-Sn Catalyst: Single site, Two Modes of Catalysis
}

Evgeny V. Beletskiy ${ }^{a}$, Xianliang Hou, ${ }^{a, \mathrm{e}}$ Zhongliang Shen, ${ }^{a}$ James R. Gallagher, ${ }^{c}$ Jeffrey T.

Miller, ${ }^{d}$ Yuyang Wu, ${ }^{b}$ Tiehu Li, ${ }^{e}$ Mayfair C. Kung, ${ }^{a^{*}}$ and Harold H. Kung. ${ }^{a^{*}}$

\section{Table of Contents}

Page

I. Materials

$\begin{array}{ll}\text { II. Instruments for characterization } & \text { S4 }\end{array}$

$\begin{array}{lll}\text { III. Materials synthesis and characterization } & \text { S6 }\end{array}$

Fig. S1. ${ }^{119}$ Sn NMR of POSS-Sn-POSS treated with 1,1,3,3,5,5- S8 hexamethyltrisiloxane.

Fig. S2a. ${ }^{119}$ Sn CPMAS NMR of II $\quad$ S9

Fig. S2b. EXAF of II and the liquid precursor POSS-Sn-POSS, I $\quad$ S10

$\begin{array}{ll}\text { Fig. S3a. DRIFTS of II and III } & \text { S11 }\end{array}$

$\begin{array}{ll}\text { Fig. S3b. EXAFS of } \mathrm{SnO}_{2} \text { and III } & \mathrm{S} 12\end{array}$

Table S1. Coordination numbers and Sn-O bond distances derived from EXAFS S12

IV. Nature and amount of Sn active site probed with pyridine

Fig. S4 DRIFT of pyridine adsorbed on II and III S13

Fig. S5a. DRIFTS of III after treating with pyridine $\quad$ S15

$\begin{array}{ll}\text { Fig. S5b. Calibration curve for pyridine } & \text { S15 }\end{array}$

Table S2. Lewis acid bound pyridine quantification by ${ }^{1} \mathrm{H}$ NMR $\quad$ S16

V. Sn catalyzed epoxide ring opening $\quad$ S16

Table S3. Epoxide consumption in a reaction with benzyl alcohol as a function of time with catalyst II

Fig. S6. Least squares linear fit of the data in Table S3. 
Table S4. Epoxide consumption as a function of time with catalyst III-low

Fig. S7. Least squares linear fit of the data in Table S3

Table S5. Effect of pyridine poisoning on catalyst III in styrene oxide ring opening with 2-propanol

Table S6. Epoxide formation as a function of time over III

Fig. S8a. Kinetic plots for rate constants tabulated in Table S4in Table S4

Fig. S8b. ${ }^{13} \mathrm{C}$ CPMAS NMR of 2-propanol on III with and without pyridine

S22

Fig. S8c. ${ }^{13} \mathrm{C}$ NMR of Sn-2-propoxide

Fig. S8d. UV-Vis of III with adsorbed 2-propoxide

Fig. S8e. DRIFTS of III with adsorbed 2-propanol and pyridine

Vc. 2-Propanol quantification

Vd. Catalyst leaching test

S25

Table S7. Epoxide consumption as a function of time with catalyst III

Fig. S9. Kinetic data plot for Table S7

S26

Ve. Catalyst reusing experiments

Table S7b. Epoxide consumption as a function of time with catalyst III

Fig. S9b. Kinetic data plots for Table S7b

VI. Hydride transfer and acetalization reactions with and without pyridine

Table S8. Effect of polarity of reaction medium on product yield in p-nitrobenzaldehyde reaction with benzyl alcohol over II and III.

Table S9. Pyridine effect on p-nitrobenzaldehyde reaction with benzyl alcohol.

VIII. Glucose isomerization 
Table S10. Glucose reaction at $140{ }^{\circ} \mathrm{C}$

IX. Cellobiose conversion

S33 


\section{Materials}

Fumed silica (EH-5) was a gift from Cabot Corporation. (c-hexyl)-POSS was obtained from Hybrid Plastics. 1,1,3,3,5,5-hexamethyltrisiloxane (>95\% purity) was purchased from Gelest. Dimethylchlorosilane (98\% purity), benzyl alcohol (99.8\% purity), and styrene epoxide (97\% purity), p-nitrobenzaldehyde (>99\% purity), pyridine (99.8\% purity) and cellobiose (98\% purity) were obtained from Aldrich. 2-Propanol (ACS grade) was purchased from Macron Fine Chemicals.

\section{Instruments for characterization}

IIa. NMR. Varian VNMRS-400 spectrometer was used to collect solid ${ }^{119}$ Sn NMR of sample II, while Agilent DD MR-400 system was used to collect NMR of liquid samples. Solid state NMR was externally referenced with $\left(c-\mathrm{C}_{6} \mathrm{H}_{11}\right)_{4} \mathrm{Sn}(-97.35 \mathrm{ppm})$, and the solution NMR was autoscaled based on the deuterated solvent in use.

IIb. EXAFS spectra. X-ray absorption measurements were acquired at the Sn K-edge (29.200 keV) on the bending magnet beam line of the Materials Research Collaborative Access Team (MRCAT) at the Advanced Photon Source, Argonne National Laboratory. The data was collected in transmission step-scan mode. Photon energies were selected using a water-cooled, double-crystal Si (111) monochromator, which was detuned by approximately $50 \%$ to reduce harmonic reflections. The ionization chambers were optimized for the maximum current with linear response $\left(\sim 10^{10}\right.$ photons detected/sec) with $10 \%$ absorption in the incident ion chamber and $70 \%$ absorption in the transmission X-ray detector. A Sn foil spectrum was acquired simultaneously with each sample measurement for energy calibration. 
Catalyst samples were pressed into a cylindrical sample holder consisting of six wells, forming a self-supporting wafer. Air sensitive samples were prepared in a $\mathrm{N}_{2}$ glove box and the sample holder was placed in a quartz tube (1-in. OD, 10-in. length) sealed with Kapton windows by two Ultra-Torr fittings. Samples were pressed directly as received while $\mathrm{SnO}_{2}$ was diluted with $\mathrm{SiO}_{2}$ to achieve an absorbance ( $\left.\mu x\right)$ of approximately 1.0. The Sn precursor was measured as a liquid in a J-Young NMR tube in toluene.

Standard data reduction techniques were employed to fit the data using the WINXAS 3.2 software program. The normalized, energy-calibrated absorption spectra were obtained using standard methods. The edge energy was determined from the maximum of the first peak by taking the first derivative of the XANES spectrum. Experimental phase shift and backscattering amplitude were measured using $\mathrm{SnO}_{2}$ as a standard of known structure (6 Sn-O at $2.05 \AA$, within $0.02 \AA$ ). The EXAFS parameters were obtained by a least square fit in $k$-space of the $k^{2}$-weighted Back-Fourier Transform data: A Fourier Transform was taken in $k$-space of the $k^{2}$-weighted data over the range 2.8-12.2 $\AA^{-1}$ before a backFourier-Transform was performed on the Sn-O scattering peak over the range 1.2-1.8 $\AA$.

IIc. UV-Vis spectroscopy. Diffuse reflectance UV-Vis spectra were recorded in the 200$400 \mathrm{~nm}$ range using Shimadzu 3600 UV-visible-NIR spectrometer. Samples were analyzed as prepared or after storage in nitrogen without further treatment, and the UVVis chamber was exposed to the atmosphere. Polytetrafluoroethylyne was used as a background. The average of five scans were collected for each sample. Final spectra were obtained by Kubelka-Munk processing of each spectrum against silica EH-5.

IId. DRIFT. A Nicolet Nexus 670 Fourier-transform infrared (FTIR) spectrometer equipped with a mercury cadmium telluride (MCT) detector was used for diffuse 
reflectance FTIR. A Harrick Praying Mantis high temperature reaction chamber was used for the pretreatment of the samples as well as for adsorption studies. II and III were pretreated at $100^{\circ} \mathrm{C}$ and $150^{\circ} \mathrm{C}$, respectively (temperatures corresponding to the highest temperature they had experienced during their synthesis) for $1 \mathrm{~h}$ in a helium flow (20 $\mathrm{mL} / \mathrm{min}$ ) in the reaction chamber. It was subsequently cooled down to room temperature. Pyridine vapor was introduced by flowing He over quartz wool soaked with pyridine solution for 10 min and subsequently the reaction chamber was maintained in pure $\mathrm{He}$ flow. Room temperature spectra were collected after $60 \mathrm{~min}$ in He at $150^{\circ} \mathrm{C}$.

IIe. ICP. Thermo iCAP 7600 Inductively Coupled Plasma Optical Emission Spectrometer (ICP-OES) was utilized. Samples (20-30 mg) were dissolved in concentrated hydrofluoric acid (3-5 drops), and diluted with $0.5 \%$ aqueous nitric (50 $\mathrm{mL}$ ). Four standards containing same amounts of acids were used for the calibration.

\section{Material synthesis and characterization}
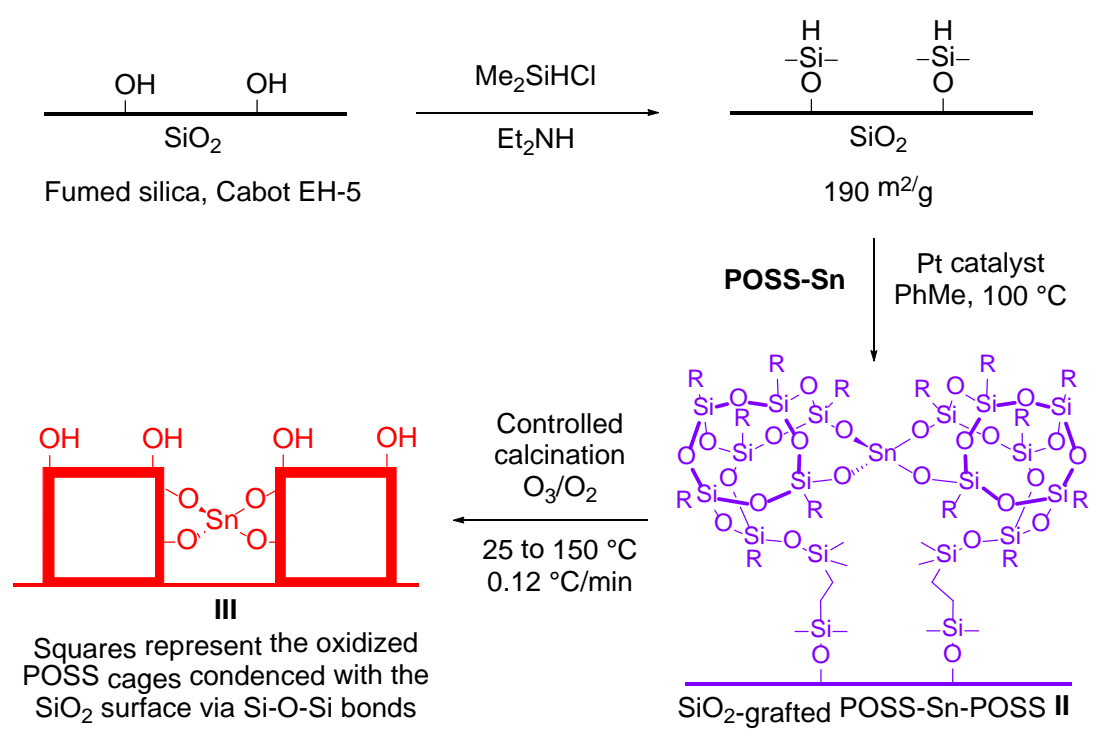

Scheme S1. Preparation of silica-supported catalysts II and III. 


\section{IIIa. Dimethylsilyl surface-modified silica}

IIIa1. Synthesis. Fumed silica (EH-5) was pretreated with water at $90{ }^{\circ} \mathrm{C}$ for $4 \mathrm{~h}$, filtered and then dried at $400{ }^{\circ} \mathrm{C}$ in vacuum for $3 \mathrm{~h}$. Diethylamine $(4.15 \mathrm{~mL}, 40 \mathrm{mmol})$ was added to a suspension of pretreated silica $(7.40 \mathrm{~g})$ in dry dichloromethane (50 mL) and, after $30 \mathrm{~min}$ of sonication, dimethyl chlorosilane $(4.44 \mathrm{~mL}, 40 \mathrm{mmol})$ was added dropwise at $0{ }^{\circ} \mathrm{C}$ with stirring. The suspension was stirred at ambient temperature for $3 \mathrm{~h}$, after which it was filtered and washed with dichloromethane (250 mL), ethanol (100 $\mathrm{mL})$, water $(10 \mathrm{~mL})$, ethanol $(50 \mathrm{~mL})$, and, finally, dichloromethane (50 $\mathrm{mL})$. The powder was ground with agate mortar and pestle, and dried in vacuum at $150{ }^{\circ} \mathrm{C}$ for 30 min. The resulting white powder (6.53 g) was stored under nitrogen. The BET surface area, measured by $\mathrm{N}_{2}$ adsorption, was $190 \mathrm{~m}^{2} / \mathrm{g}$.

\section{IIIa2. Determination of average distance between $\mathrm{Si}-\mathrm{H}$ groups on Dimethylsilyl silica}

. To a suspension of dimethylsilyl surface-modified silica (500 mg) in dry toluene (3.0 $\mathrm{mL}$ ), was added 1-dodecene (111 $\mu \mathrm{L}, 500 \mu \mathrm{mol})$, diphenyl methane (internal standard, $150 \mu \mathrm{mol})$ and Karsted's catalyst $(10 \mu \mathrm{L})$. The mixture was heated at $100{ }^{\circ} \mathrm{C}$ with vigorous stirring for $20 \mathrm{~h}$. An aliquot was withdrawn and filtered through a plug of celite, followed by washing with $\mathrm{CDCl}_{3} .{ }^{1} \mathrm{H}$ NMR analysis showed that $270 \mu \mathrm{mol}$ of dodecene has been removed from the solution, indicating that the silica sample has $540 \mu \mathrm{mol} / \mathrm{g}$ reactive $\mathrm{Si}-\mathrm{H}$ groups. Together with the BET surface area of $190 \mathrm{~m}^{2} / \mathrm{g}$ this gives an average of $1.7 \mathrm{Si}-\mathrm{H} / \mathrm{nm}^{2}$ and an average distance of $0.76 \mathrm{~nm}$ between the $\mathrm{Si}-\mathrm{H}$ groups. 


\section{III b Synthesis of II: grafting of POSS-Sn-POSS onto dimethylsilyl surface-modifed}

silica

IIIb1. Simulation of grafting reaction. To a solution of POSS-Sn-POSS $(30 \mu \mathrm{mol})$ in toluene- $d_{8}(0.5 \mathrm{~mL}), 1,1,3,3,5,5-h e x a m e t h y l t r i s i l o x a n e ~(25 \mu \mathrm{L}, 98 \mu \mathrm{mol})$ and Karsted's catalyst $(5 \mu \mathrm{L})$ were added. Complete disappearance of alkene NMR resonances was observed after $15 \mathrm{~min}$ at ambient temperature. After $17 \mathrm{~h}$ at $100{ }^{\circ} \mathrm{C}$, a single resonance at $-443 \mathrm{ppm}$ was observed in the ${ }^{119} \mathrm{Sn}$ NMR spectrum (Fig. S1), characteristic of tetrahedral Sn.
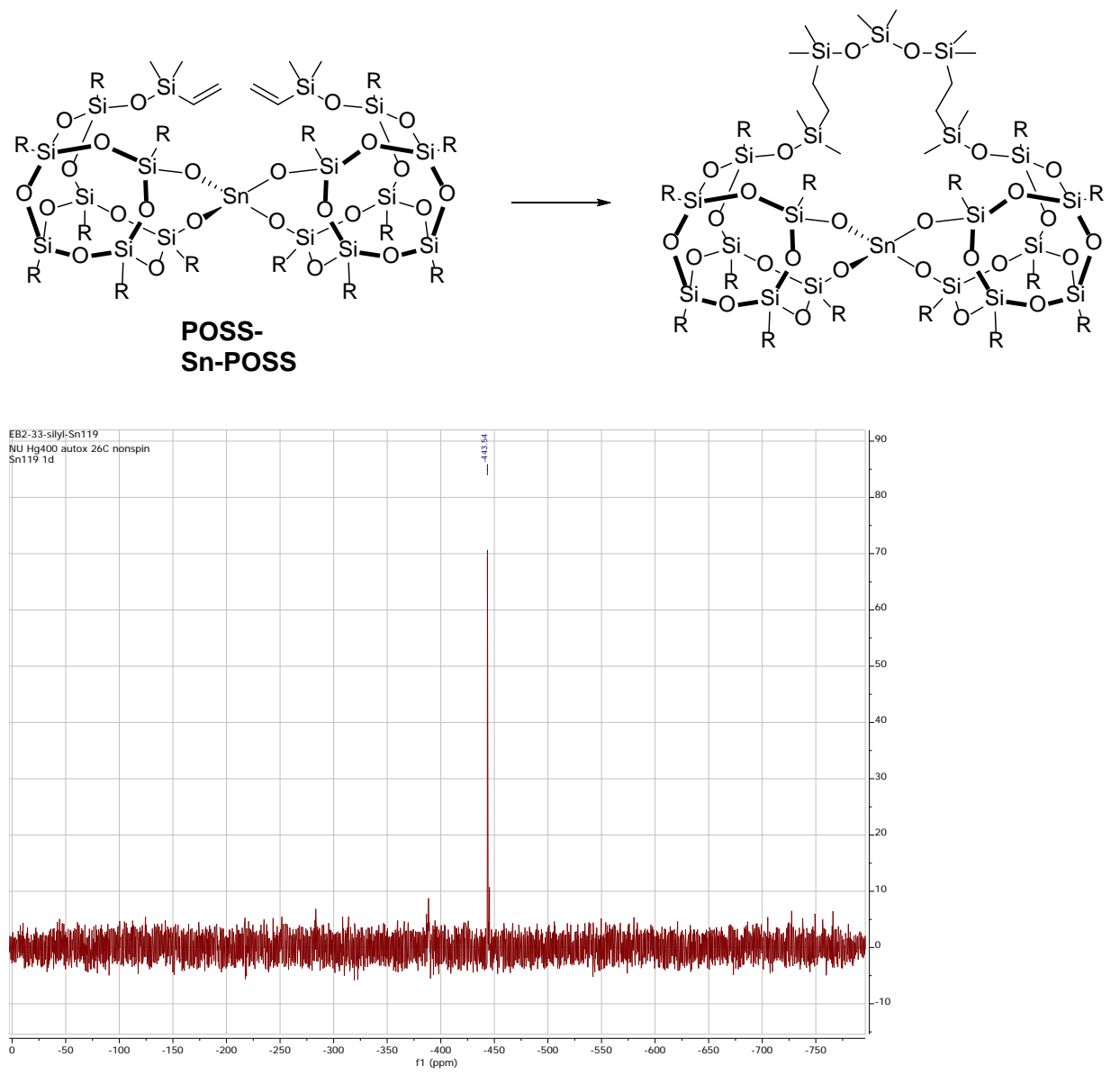

Figure S1. ${ }^{119}$ Sn NMR of reaction product of POSS-Sn-POSS with 1,1,3,3,5,5hexamethyltrisiloxane under grafting reaction conditions. 


\section{IIIb2. POSS-Sn-POSS on surface-modified modified silica (structure II): synthesis and}

characterization Dimethylsilyl surface-modified silica (3.0 g) was pretreated in vacuum at $200{ }^{\circ} \mathrm{C}$ for $30 \mathrm{~min}$ in a Schlenck flask. POSS-Sn-POSS (520 $\mu \mathrm{mol}, 2 \mathrm{wt} \% \mathrm{Sn}$ ) was added in dry toluene $(12 \mathrm{~mL})$ under nitrogen. Karsted's catalyst $(0.05 \mathrm{~mL})$ was added and the mixture was stirred at $100{ }^{\circ} \mathrm{C}$. Internal standard (diphenylmethane) indicated $18 \%$ and 50\% decrease in vinyl signal intensity in the NMR spectra after 5 and 26 h, respectively. The grafted silica was filtered, washed with dichloromethane $(100 \mathrm{~mL})$, dried in vacuum, and stored in a nitrogen flushed vial. CPMAS ${ }^{119}$ Sn CPMAS NMR showed a peak at $\delta$ 439 ppm, consistent with tetrahedral Sn (Figure S2a). EXAFS spectrum also showed that the Sn-O coordination remained 4 (Figure S2b and Table S1) but the disorder was higher than in the POSS-Sn-POSS solution precursor presumably due to inhomogeneity of the support surface that resulted in a wider conformational distribution. Based on the size of POSS-Sn-POSS obtained from its single crystal X-Ray analysis $\left(2.5 \mathrm{~nm}^{2}\right), 70 \%$ of the maximum loading was achieved (90 out of $130 \mu \mathrm{mol} / \mathrm{g}$ ), and 30\% of Si-H's were reacted. A lower Sn loading sample was also prepared for comparison (sample II-low). The preparation method was the same as that for II except a smaller amount of POSS-SnPOSS was added at the grafting stage (ca. $15 \mu \mathrm{mol}$ POSS-Sn-POSS per $1 \mathrm{~g}$ silica). ${ }^{1} \mathrm{H}$ NMR of the reaction solution revealed full incorporation of POSS-Sn-POSS onto silica at this lower Sn loading. 


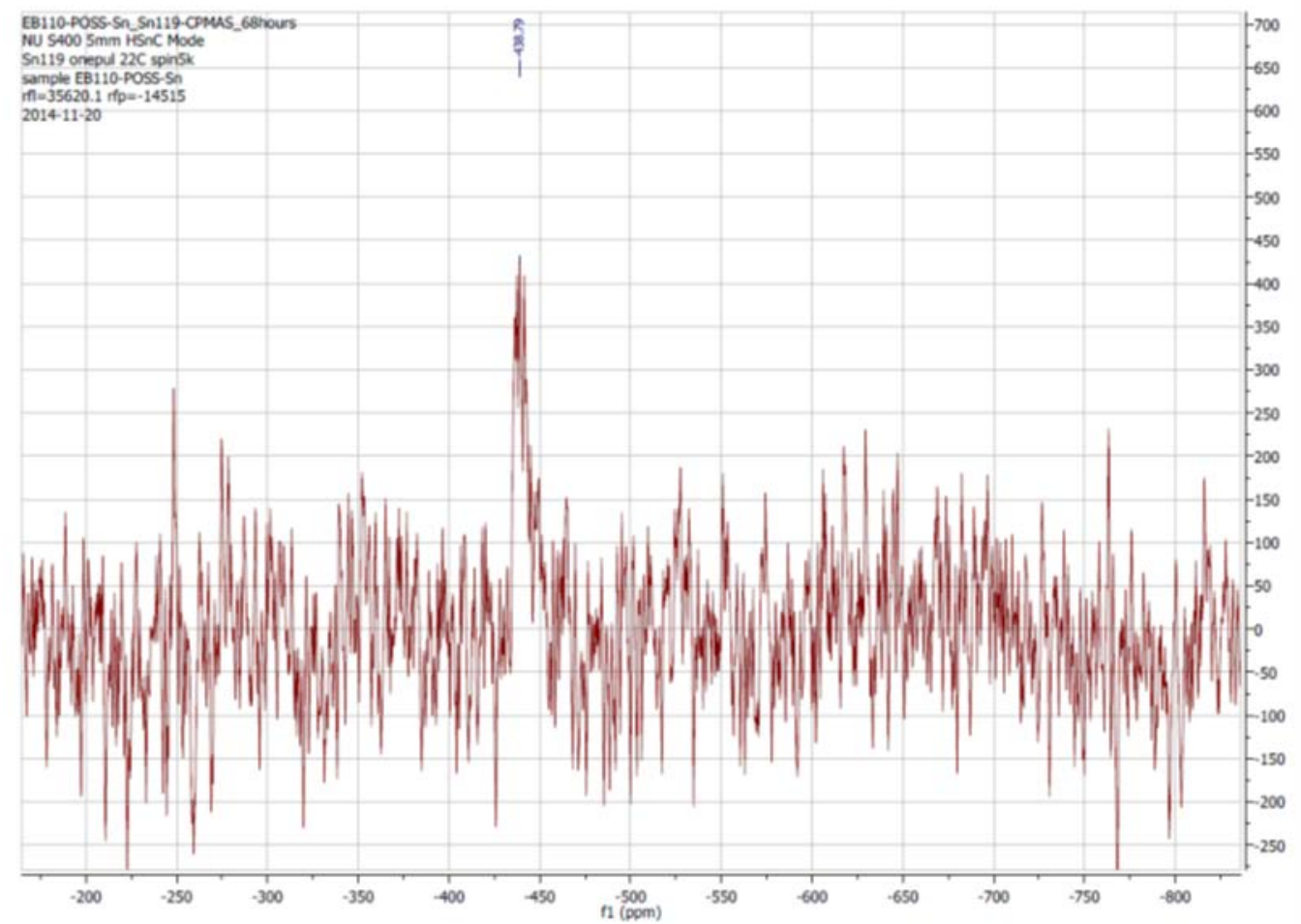

Figure S2a. ${ }^{119}$ Sn CPMAS NMR of II

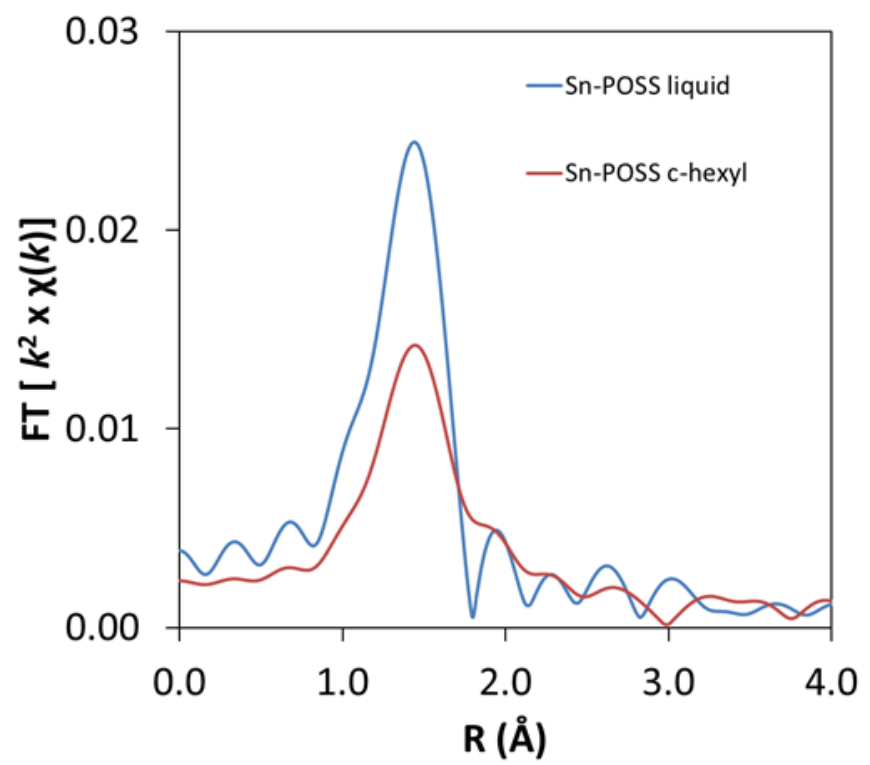

Figure S2b. EXAF of II and the liquid precursor POSS-Sn-POSS 
IIIc.Calcined Sn-POSS grafted silica (structure III). III (0.5-3g) was loaded in a Ushaped reactor equipped with a fritted separator. The flow of dry oxygen $(300 \mathrm{~mL} / \mathrm{min})$ was established through the tube and the ozone was introduced gradually by an ozone generator. The reactor was heated in a flow 10\% ozone/oxygen mixture from 25 to 150 ${ }^{\circ} \mathrm{C}$ with a gradual temperature increase of $0.12^{\circ} \mathrm{C} / \mathrm{min}$, followed by $2 \mathrm{~h}$ at $150{ }^{\circ} \mathrm{C}$ to form III. After calcination, III was stored in a nitrogen flushed vial. ICP analysis gave $1.1 \mathrm{wt}$ \% Sn, consistent with $50 \%$ of the added POSS-Sn-POSS being deposited on silica in the formation of II. When the calcination step was used with II-low, III-low was formed with 0.21 wt \% Sn. DRIFTS indicated disappearance of Si-H $\left(2200 \mathrm{~cm}^{-1}\right)$ and $\mathrm{C}-\mathrm{H}$ (2800-3000 $\mathrm{cm}^{-1}$ ), suggesting complete oxidation (Figure S3a).

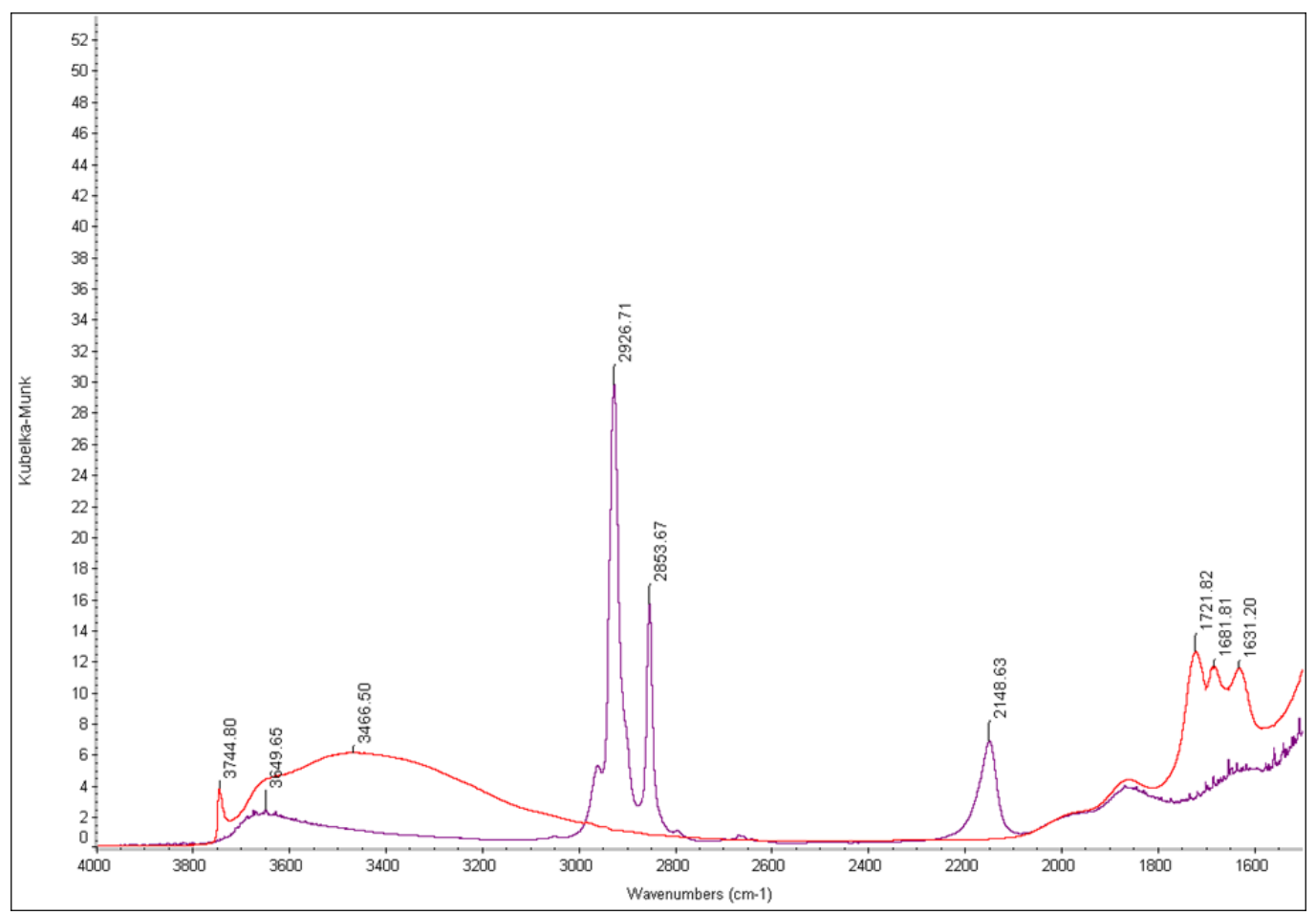

Figure S3a. DRIFTS of II (purple) and III (red) after heating in helium flow for 30 min at $120^{\circ} \mathrm{C}$ (II) and $160^{\circ} \mathrm{C}$ (III). 


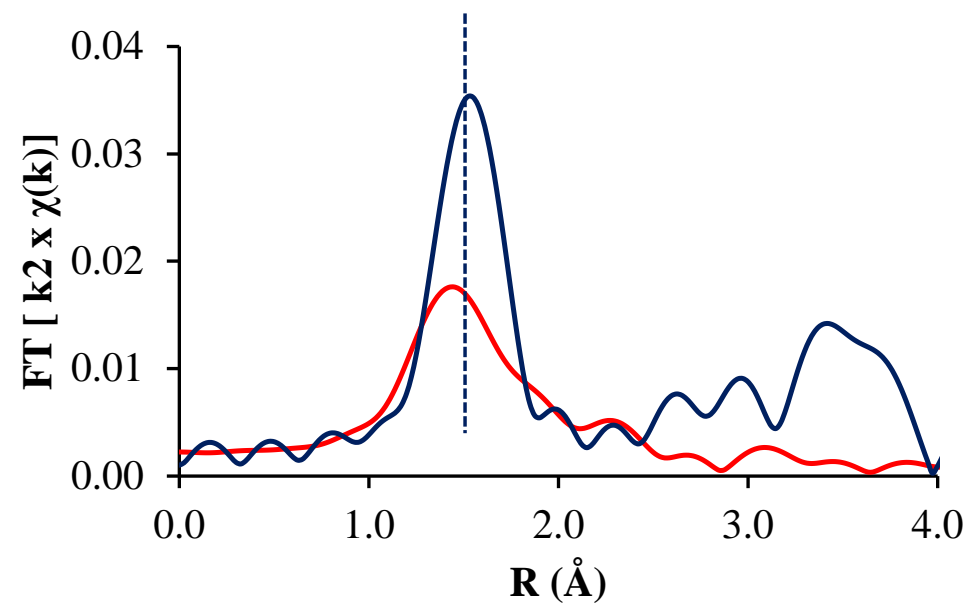

Figure S3b. EXAFS of $\mathrm{SnO}_{2}$ (blue) and III (red).

Table S1. Results from $k$-space fitting of the EXAFS data, measured at room temperature. Fitting range; $k^{2}: \Delta k=2.8-12.2 \AA^{-1} ; \Delta R=1.2-1.8 \AA . \quad N=$ coordination number; $R=$ bond distance; $\Delta \sigma^{2}=$ mean-square disorder in the distribution of interatomic distances; $\Delta E_{0}=$ energy offset. The estimated errors are: $C N, \pm 10 \%$ and $R, \pm 0.02 \AA$.

\begin{tabular}{|c|c|c|c|c|c|}
\hline Sample & $\begin{array}{l}\text { Edge } \\
\text { energy } \\
(\mathrm{eV})\end{array}$ & $\begin{array}{l}\mathrm{N} \pm \\
10 \%\end{array}$ & $R \pm 0.02(\AA ̊)$ & $\Delta \sigma^{2}$ & $\Delta \mathrm{E}_{0}$ \\
\hline $\mathrm{Sn}(\mathrm{POSS})_{2}(\mathrm{I})$ in solution & 29203.2 & 4.1 & 1.95 & 0.0010 & 2.9 \\
\hline $\begin{array}{l}\text { Sn(POSS })_{2} / \text { silica } \quad \text { II } \quad \text { (as } \\
\text { prepared) }\end{array}$ & 29202.6 & 3.5 & 1.99 & 0.0054 & -0.1 \\
\hline $\mathrm{Sn}(\mathrm{POSS})_{2} /$ silica III (calcined) & 29204.5 & 4.5 & 2.02 & 0.0054 & -1.7 \\
\hline $\begin{array}{l}\text { SnO2 (ref Elliot } 2010 \text { for } \\
\text { coordination*) }\end{array}$ & 29204.5 & 6.0 & 2.05 & N/A & N/A \\
\hline
\end{tabular}

*all bonds within $0.02 \mathrm{~A}$ of each other thus treated as single scattering path 


\section{Nature and amount of Sn active site probed with pyridine}

\section{IVa. Adsorption and desorption of pyridine from II and III with DRIFT}

These experiments were conducted to characterize the nature of the Lewis acid sites present in II and III.

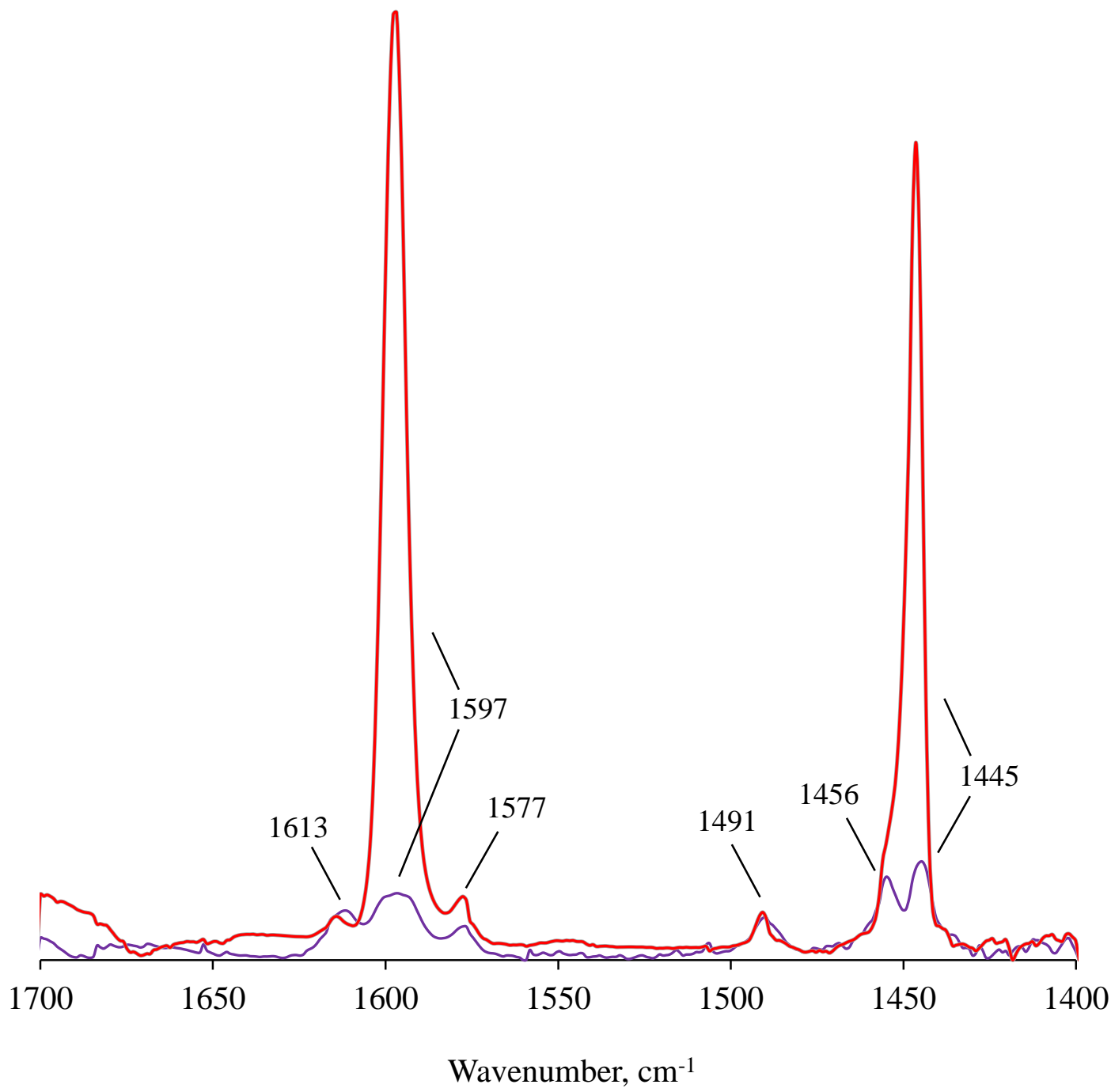

Fig. S4. FTIR spectra collected at $20^{\circ} \mathrm{C}$ of adsorbed pyridine on II (purple) and III (red).

Py was introduced in a flow of $\mathrm{He}$ at $20^{\circ} \mathrm{C}$ for $10 \mathrm{~min}$, and subsequently the samples 
were purged in $\mathrm{He}$ at $150^{\circ} \mathrm{C}$ at $30 \mathrm{ml} \mathrm{min}^{-1}$ for $1 \mathrm{~h}$. At this slow flowrate, some physisorbed pyridine remained.

IVb. Bound pyridine quantification. Dichloromethane $(3.0 \mathrm{~mL})$ and pyridine $(0.1 \mathrm{~mL})$ were added to a sample of III (77-85 mg). The resulting suspension was sonicated for 2 min and the volatiles were removed in a high flow of nitrogen, followed by drying at a specified temperature again in a high $\mathrm{N}_{2}$ flow ( $\left.300 \mathrm{~mL} / \mathrm{min}\right)$. As shown in Table S2, at this high $\mathrm{N}_{2}$ purge rate, no physisorbed or hydrogen bonded py was present on silica at $150{ }^{\circ} \mathrm{C}$ after $0.5 \mathrm{~h}$. Additionally, no physisorbed pyridine was observed on III under these conditions as determined by DRIFTS (Figure S5a). Afterwards, aqueous sodium hydroxide ( $2.5 \mathrm{wt} \%, 5 \mathrm{~mL}$ ) was added to the mixture and stirred for $10 \mathrm{~min}$. Chloroform- $d(1.02 \mathrm{~mL})$ with diphenylmethane $(1.00 \mu \mathrm{L})$ as an internal standard was then added. After stirring for 5 min, the organic layer was separated. Pyridine in the organic layer was quantified by ${ }^{1} \mathrm{H}$ NMR using a calibration curve that was derived from similar extraction experiments using samples of known amounts of pyridine added to silica (Figure S5b). 


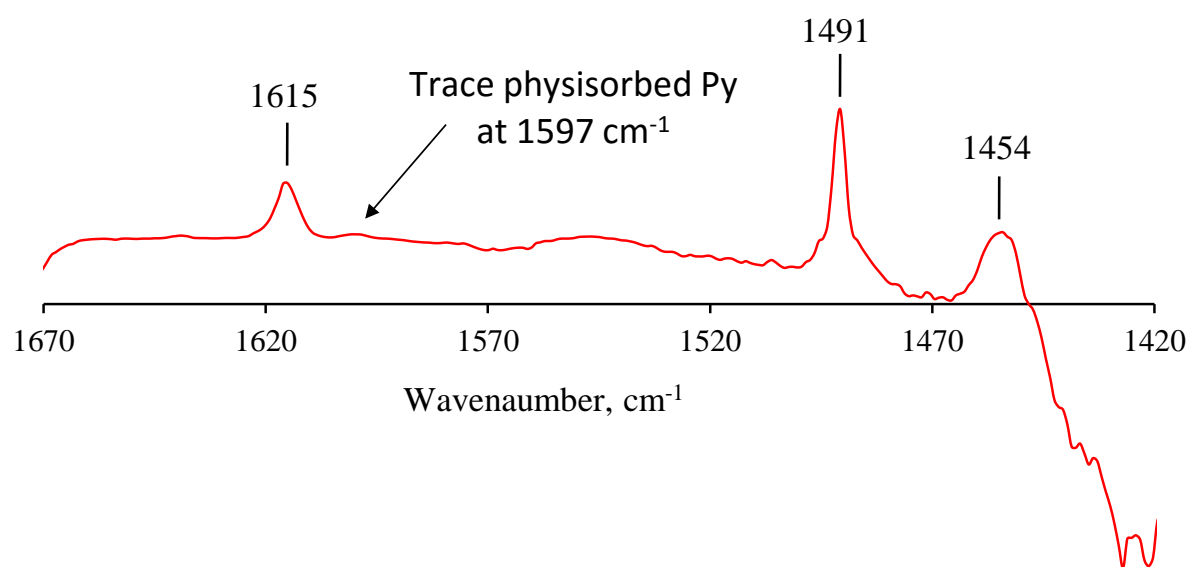

Figure S5a. DRIFTS of III after treating with pyridine in dichloromethane, evaporating the liquids and drying at $150^{\circ} \mathrm{C}$ in $\mathrm{N}_{2}$ flow (300 $\mathrm{mL} / \mathrm{min}$ ). Background spectra was collected using III after suspending in dichloromethane and drying under same conditions. Spectra contains Lewis and some Brønsted acid bound but no physisorbed pyridine.

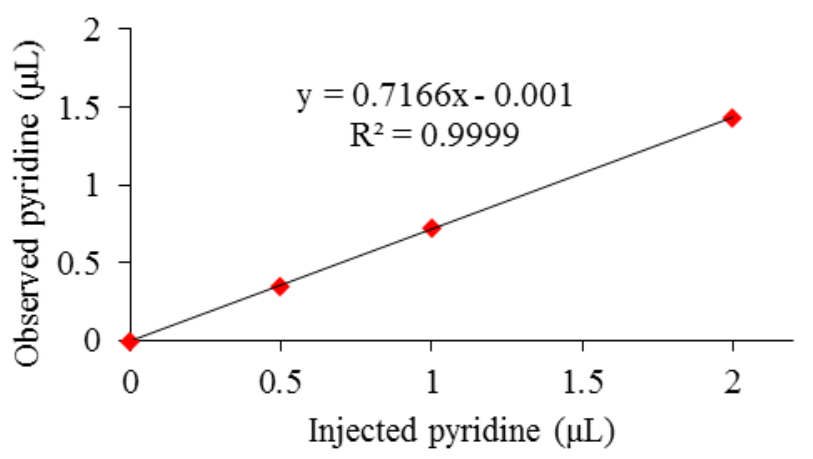

Figure S5b. Calibration curve for Lewis acid site quantification. 
Table S2. Lewis acid bound pyridine quantification by ${ }^{1} \mathrm{H}$ NMR.

\begin{tabular}{|c|c|c|}
\hline Sample & Conditions & Py : Sn \\
\hline III & $150{ }^{\circ} \mathrm{C}, 30 \mathrm{~min}$ & $0.95: 1$ \\
\hline III & $150^{\circ} \mathrm{C}, 60 \mathrm{~min}$ & $0.86: 1$ \\
\hline III & $200{ }^{\circ} \mathrm{C}, 60 \mathrm{~min}$ & $0.52: 1$ \\
\hline $\mathrm{SiO}_{2}$ & $150{ }^{\circ} \mathrm{C}, 30 \mathrm{~min}$ & $0.02: 1$ \\
\hline $\mathrm{SiO}_{2}$ & $150^{\circ} \mathrm{C}, 60 \mathrm{~min}$ & $0.00: 1$ \\
\hline
\end{tabular}

\section{Sn catalyzed epoxide ring opening}

Va. Ring opening of styrene epoxide with benzyl alcohol. A suspension of the catalyst (10 mg, $0.105 \mathrm{~mol} \%$ ) in benzyl alcohol $(0.25 \mathrm{~mL}$ for III and $1.0 \mathrm{~mL}$ for II) and diphenyl methane (25 $\mu \mathrm{L})$ as an internal standard was sonicated for 2 min. Styrene oxide $(0.1 \mathrm{~mL})$ was added. Periodically, a small sample was withdrawn with a syringe and filtered through celite in $\mathrm{CDCl}_{3}$ for NMR analysis. High conversions and 68-72\% yield were observed with III at ambient temperature after $10 \mathrm{~min}$. As shown in Fig. S6 (and also S8), the data followed first order kinetics. For II at $80{ }^{\circ} \mathrm{C}$, the time for $50 \%$ conversion, $\mathrm{T}_{1 / 2} \approx 180$ min. (Table S3, Figure S6).
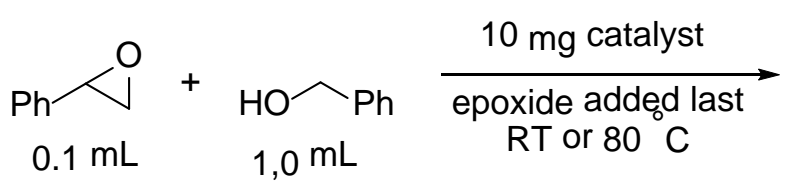<smiles>OCC(OCc1ccccc1)c1ccccc1</smiles> 
Table S3. Epoxide consumption in a reaction with benzyl alcohol as a function of time with catalyst II.

\begin{tabular}{|c|c|c|}
\hline Time (min) & Epoxide (\%) & $\ln \left(\mathrm{C}_{0} / \mathrm{C}\right)$ \\
\hline 60 & 82.3 & 0.195 \\
\hline 120 & 67 & 0.400 \\
\hline 180 & 52 & 0.654 \\
\hline 243 & 38 & 0.968 \\
\hline 332 & 22 & 1.514 \\
\hline
\end{tabular}

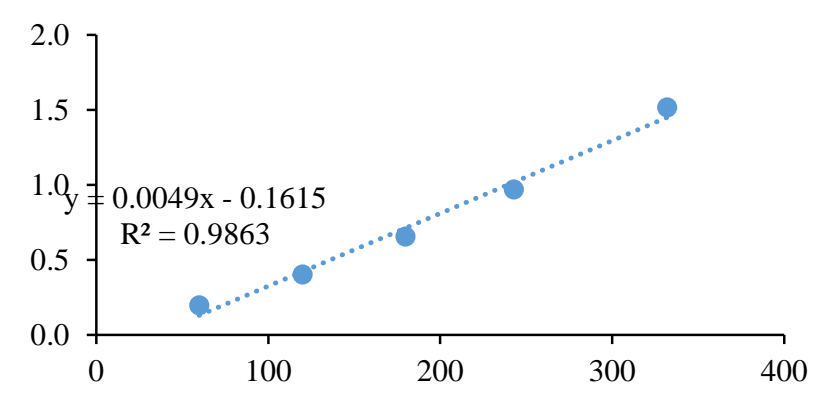

Figure S6. Least squares linear fit of the data in Table S3.

$\mathrm{Vb}$. Ring opening of styrene epoxide with isopropanol with and without pyridine poisoning. Suspensions of catalyst III (10 mg, $0.105 \mathrm{~mol} \%$ ) or III-low (52.4 mg, 0.105 mol \%) in isopropyl alcohol $(1.0 \mathrm{~mL})$ with various amounts of pyridine were sonicated for 2 min at ambient temperature and then stirred for 2 additional min at $80{ }^{\circ} \mathrm{C}$. The mixture was placed in an oil bath at $50{ }^{\circ} \mathrm{C}$, and after $4 \mathrm{~min}$, styrene oxide $(0.1 \mathrm{~mL})$ was added. The reaction conversion and product yield were obtained by ${ }^{1} \mathrm{H}$ NMR analysis of the aliquots drawn at specific times and filtered through celite in $\mathrm{CDCl}_{3}$ (Tables S4-S6). 
Pseudo-first order dependence was observed even to high conversions for III and IIIlow. The pseudo-first order rate constant $\mathrm{k}_{1}$ were $2 * 10^{-2}$ and $1.5 \times 10^{-2} \mathrm{~min}^{-1}$, respectively. Even in the presence of pyridine, except for the sample where py/Sn=0.54, pseudo first order kinetics was observed and the rate constants were the slopes of the linear least squares fits in the plots of $\ln \left(\mathrm{C}_{0} / \mathrm{C}\right)$ versus time (Figure S8a). All experiments have been repeated at least once.

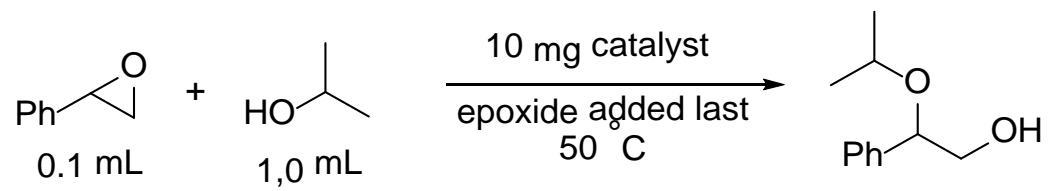

Table S4. Epoxide consumption as a function of time with catalyst III-low containing 0.21 wt \% Sn.

\begin{tabular}{|c|c|c|}
\hline Time (min) & Epoxide (\%) & $\ln \left(\mathrm{C}_{0} / \mathrm{C}\right)$ \\
\hline 30 & 58.9 & 0.529 \\
\hline 51 & 42.2 & 0.863 \\
\hline 74 & 29.9 & 1.21 \\
\hline
\end{tabular}

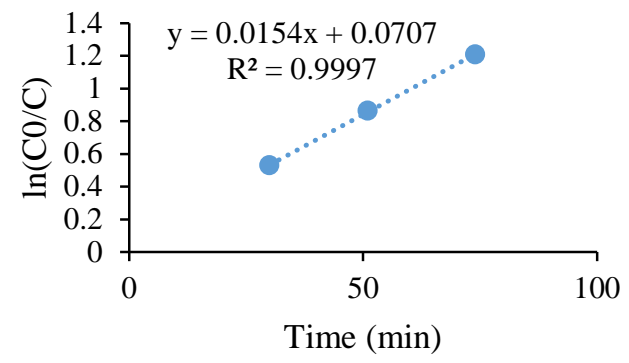

Figure S7. Least squares linear fit of the data in Table S4. 
Table S5. Effect of pyridine poisoning on catalyst III in styrene oxide ring opening with 2propanol. III (10 mg), isopropyl alcohol $(1.0 \mathrm{~mL})$, styrene oxide $(0.1 \mathrm{~mL}), 50^{\circ} \mathrm{C}$.

\begin{tabular}{|c|c|c|c|c|}
\hline Entry & $\begin{array}{c}\text { Pyridine } \\
(\mu \mathrm{L})\end{array}$ & $\mathrm{Py} / \mathrm{Sn}$ & $\begin{array}{c}\text { First order } \\
\text { rate constant } \\
\mathrm{k}^{*} 10^{2}\left(\mathrm{~min}^{-1}\right)\end{array}$ & $\begin{array}{c}\text { \% activity, relative to } \\
\text { pyridine-free runs }\end{array}$ \\
\hline 1 & 0 & 0 & 2.0 & 100 \\
\hline 2 & 0.01 & 0.14 & 2.6 & 130 \\
\hline 3 & 0.02 & 0.27 & 1.4 & 70 \\
\hline 4 & 0.03 & 0.41 & 0.94 & 47 \\
\hline $5 * *$ & 0.04 & 0.54 & 0.6 & 31 \\
\hline 6 & 0.1 & 1.52 & 0.00 & 0 \\
\hline
\end{tabular}

**: initial data were used to obtain rate constant. 
Table S6. Epoxide consumption as a function of time over III (data plotted in Fig. S8a).

\begin{tabular}{|c|c|c|c|c|}
\hline $\mathrm{Py} / \mathrm{Sn}$ & Time (min) & Yield (\%) & Epoxide (\%) & $\ln \left(\mathrm{C}_{0} / \mathrm{C}\right)$ \\
\hline \multirow[t]{6}{*}{0} & 5 & 9 & 101 & -0.0109 \\
\hline & 10 & 18.1 & 86.1 & 0.1496 \\
\hline & 15 & 27.1 & 79.7 & 0.2269 \\
\hline & 20 & 34.6 & 72.2 & 0.3257 \\
\hline & 30 & 43 & 58.9 & 0.5293 \\
\hline & 40 & 53.6 & 48.3 & 0.7277 \\
\hline \multirow[t]{4}{*}{0.14} & 5 & 12 & 85.7 & 0.1543 \\
\hline & 10 & 24 & 75.1 & 0.2864 \\
\hline & 15 & 32.9 & 63.2 & 0.4589 \\
\hline & 20 & 41 & 58.5 & 0.5361 \\
\hline \multirow[t]{4}{*}{0.27} & 5 & 8.8 & 87.9 & 0.1290 \\
\hline & 10 & 16.2 & 81 & 0.2107 \\
\hline & 20 & 26.2 & 70.9 & 0.3439 \\
\hline & 30 & 33.9 & 61.7 & 0.4829 \\
\hline \multirow[t]{4}{*}{0.41} & 5 & 5.9 & 84.6 & 0.1672 \\
\hline & 10 & 11.6 & 82.6 & 0.1912 \\
\hline & 15 & 13 & 76.6 & 0.2666 \\
\hline & 20 & 16.3 & 74.2 & 0.2984 \\
\hline \multirow[t]{4}{*}{0.54} & 10 & 5.6 & 92.7 & 0.0758 \\
\hline & 20 & 8.7 & 87.2 & 0.1369 \\
\hline & 30 & 8 & 89 & 0.1165 \\
\hline & 40 & 8.7 & 87 & 0.1392 \\
\hline
\end{tabular}



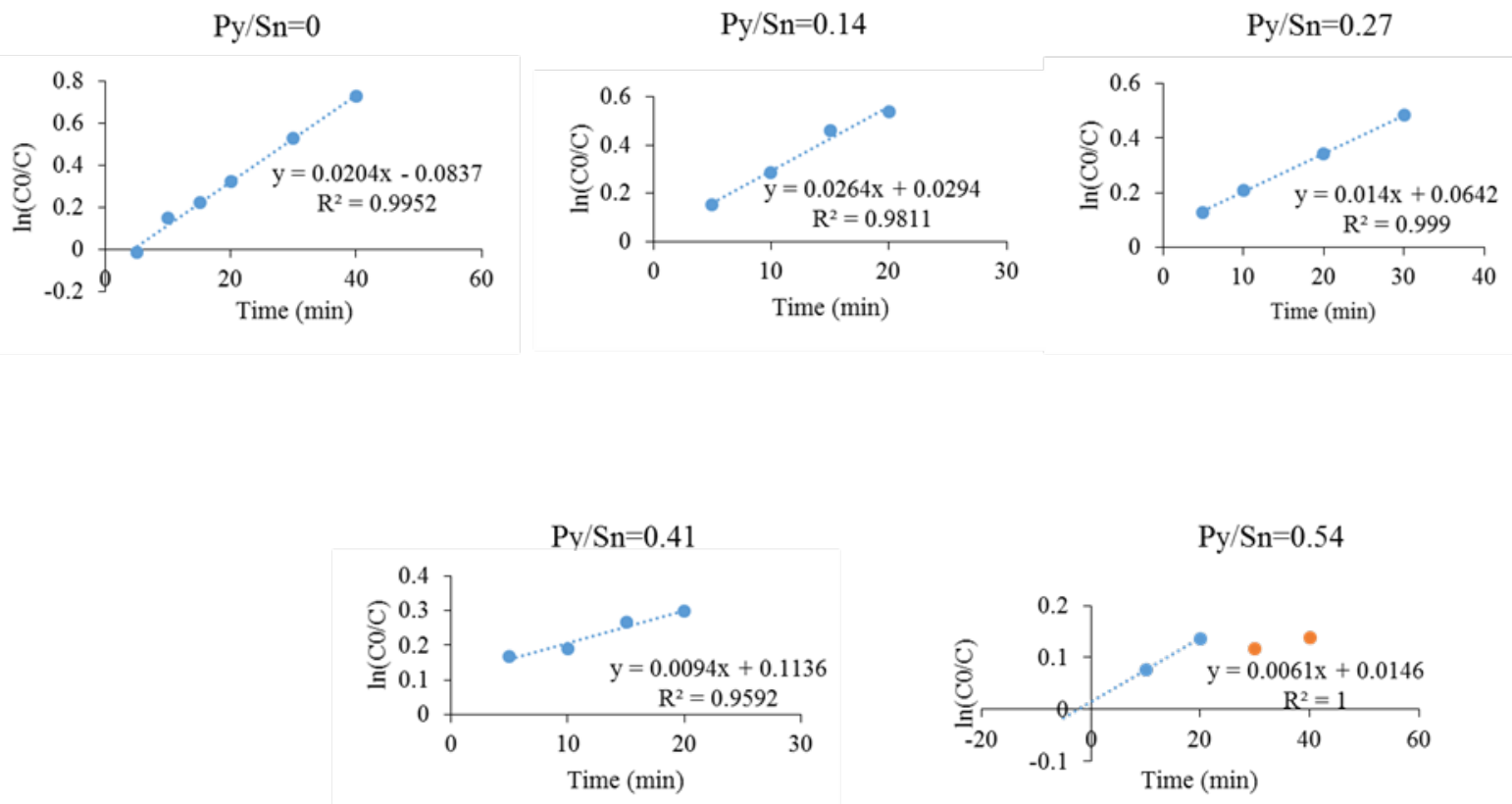

Figure. S8a. Kinetic plots for rate constants $\mathrm{k}_{\mathrm{e}}$ tabulated in Table S5. 
The solid state NMR sample treatment. The solid sample (140-170 mg) was placed in neat isopropanol $(2 \mathrm{~mL})$ and sonicated for $2 \mathrm{~min}$. Then it was dried at $150{ }^{\circ} \mathrm{C}$ for 5 minute. For the sample that was treated with pyridine, the dried sample was placed in isopropanol $(2.0 \mathrm{~mL})$ again and then $0.1 \mathrm{~mL}$ of pyridine was added $(\mathrm{py} / \mathrm{Sn}=80: 1)$ and the sample stirred. Then the sample was dried again at $150^{\circ} \mathrm{C}$ for $30 \mathrm{~min}$.

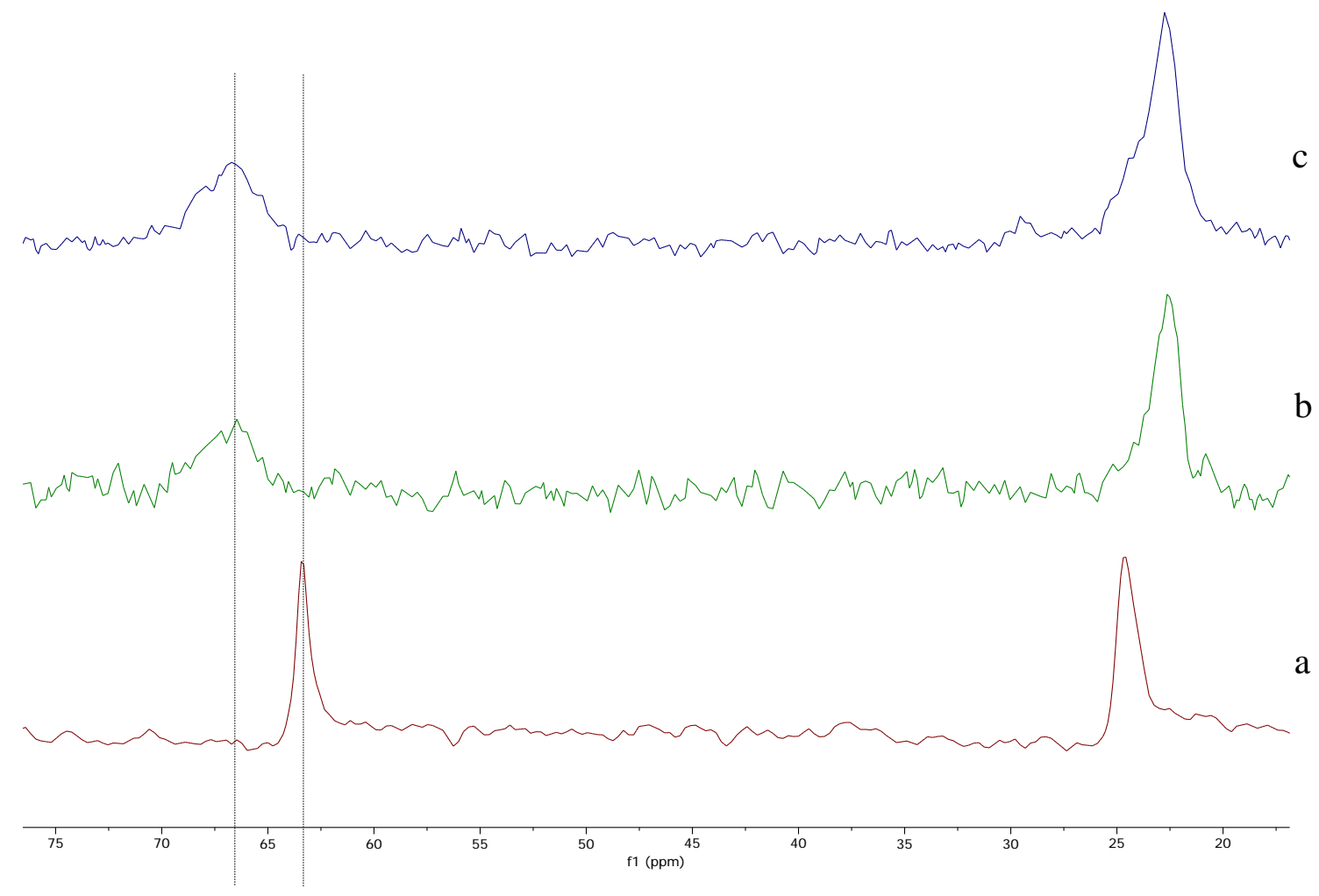

Figure S8b. ${ }^{13} \mathrm{C}$ CPMAS NMR of 2-propanol adsorbed on silica and III, in the presence and absence of added pyridine. (a) 2-propanol and pyridine added to silica at room temperature, (b) 2-propanol added to III (c) 2-propanol and pyridine added to III. b and c were acquired after drying $150^{\circ} \mathrm{C}$ to remove physisorbed molecules. Peaks between 60$70 \mathrm{ppm}$ are ascribed to the carbon next to the oxygen and peaks between 20-25 ppm are the methyl carbon resonances. 


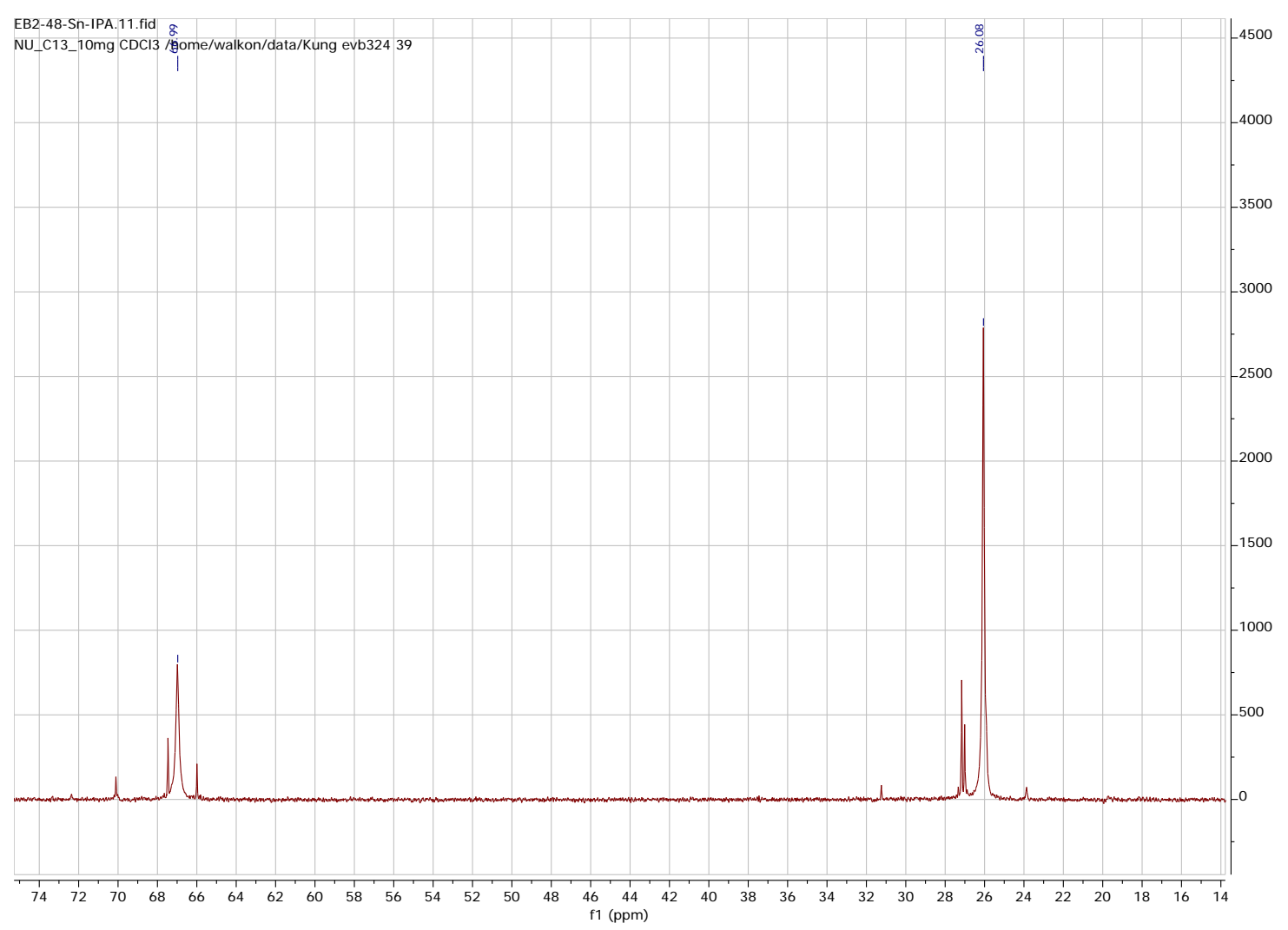

Figure S8c. ${ }^{13} \mathrm{C}$ NMR of Sn isopropoxide. 


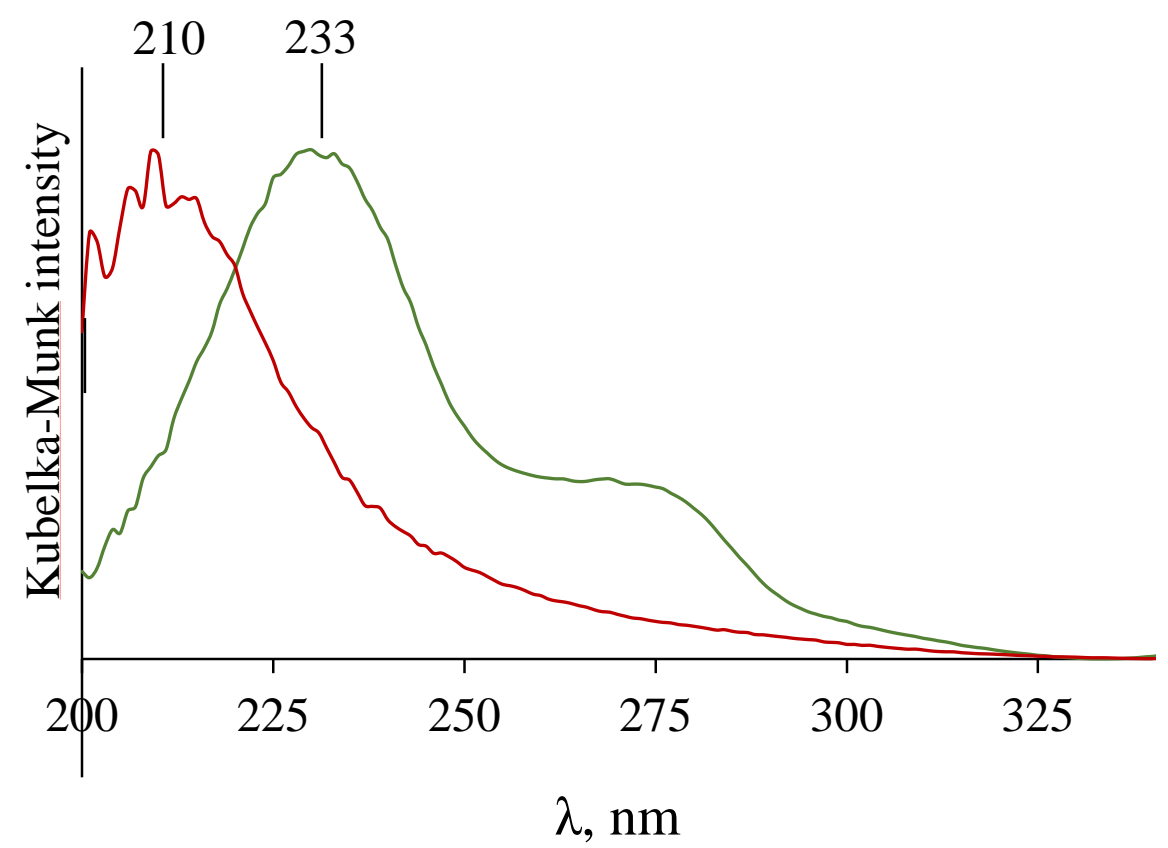

Figure S8d. Diffuse reflectance UV-Vis of III (maroon) and III with adsorbed isopropanol (green). III (26 mg) was placed in 2-propanol (1.0 mL), the solvent was removed in a $\mathrm{N}_{2}$ flow, and the powder was dried in the $\mathrm{N}_{2}$ flow at $150^{\circ} \mathrm{C}$ for $2 \mathrm{~min}$.

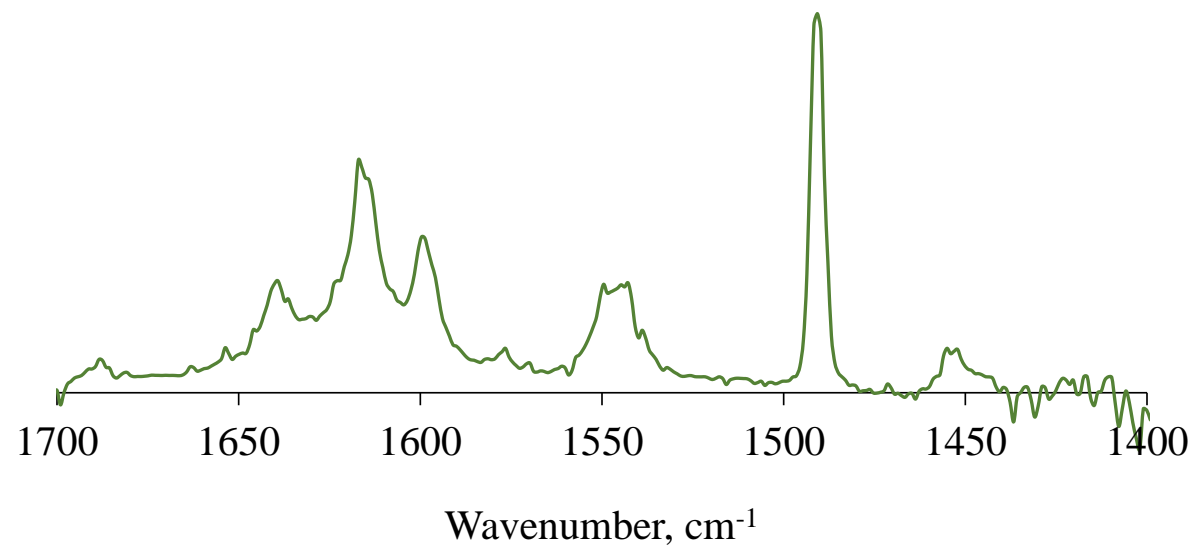

Figure S8e. DRIFT spectra of pyridine on III-isopropanol obtained by soaking III in 2propanol, treating the sample with He for 40 min (background spectra), followed by exposing to vapors from a 2-propanol/pyridine mixture (100:1, v/v) and purging with He for 20 min. 
Vc. Adsorbed 2-Propanol quantification. The suspension of the catalyst III (86.3 mg, $8.00 \mu \mathrm{mol})$ or silica EH-5 (73.9 mg) in 2-propanol (2 mL) was sonicated for $2 \mathrm{~min}$. In the $\mathrm{N}_{2}$ flow the solvent was evaporated and the powder was dried at $150^{\circ} \mathrm{C}$ for $2 \mathrm{~min}$. The procedure was repeated with more 2-propanol $(2 \mathrm{~mL})$ and the powder was dried for 30 min at $150^{\circ} \mathrm{C}$. Deuterium oxide $(1.0 \mathrm{~mL})$ and aqueous sodium hydroxide (20 wt \%, 0.1 $\mathrm{mL})$ were added and the suspension was sonicated for $30 \mathrm{~min} . \mathrm{D}_{2} \mathrm{O}$ solution $(10 \mu \mathrm{L})$ of internal standard methanol $(0.50 \mu \mathrm{L})$ was added and 2-propanol was quantified by ${ }^{1} \mathrm{H}$ NMR: silica EH-5 - $4.7 \mu \mathrm{mol}$, III - 20.7 $\mu \mathrm{mol}$. The Sn to IPA ratio was $1: 2.6$, and was accounted for coordination to Sn, as well as acid catalyzed $\mathrm{Si}-\mathrm{OH}+\mathrm{PrOH}=\mathrm{Si}-\mathrm{OPr}+$ $\mathrm{H}_{2} \mathrm{O}$ reaction, in particular on the POSS cage edges. In presence of pyridine (sample c in Figure S8b) the Sn : IPA ratio was measured to be $1: 2.8$.

Vd. Catalyst leaching test. A suspension of the catalyst III (10 mg, $0.1 \mathrm{~mol} \%)$ in isopropyl alcohol $(1.0 \mathrm{~mL})$ was sonicated for $2 \mathrm{~min}$ and then stirred for 2 additional min at ambient temperature (Expt. 1) or at $60^{\circ} \mathrm{C}$ for $10 \mathrm{~min}$ then cooled to r.t. (Expt. 2). Styrene oxide $(0.1 \mathrm{~mL})$ was added and the reaction was followed at ambient temperature by NMR as described in section $\mathrm{Vb}$. The reaction mixture was filtered after about $6 \mathrm{~h}$ of reaction (Expt. 1) or $1 \mathrm{~h}$ (Expt. 2). Afterwards, further analysis of the filtrate showed that the reaction has stopped (Table S7, and Figure S9), indicating that the catalytic species were heterogeneous. 
Table S7. Epoxide consumption as a function of time with catalyst III at ambient temperature $\left(23^{\circ} \mathrm{C}\right)$.

\begin{tabular}{|c|c|c|c|c|}
\hline \multicolumn{3}{|c|}{ Expt. 1 } & \multicolumn{2}{c|}{ Expt. 2 } \\
\hline Time (min) & Epoxide (\%) & $\ln \left(\mathrm{C}_{0} / \mathrm{C}\right)$ & Time (min) & Product yield (\%) \\
\hline 30 & 89.9 & 0.106 & 30 & 2.6 \\
\hline 60 & 80.5 & 0.217 & 60 & Filtered \\
\hline 120 & 68.4 & 0.380 & 60 & 4.5 \\
\hline 240 & 50.2 & 0.689 & 150 & 5.2 \\
\hline 360 & 36.5 & 1.008 & 210 & 5.6 \\
\hline 372 & \multicolumn{2}{|c|}{ filtered } & 270 & 4.5 \\
\hline 1560 & 35.9 & 1.033 & 340 & \\
\hline
\end{tabular}

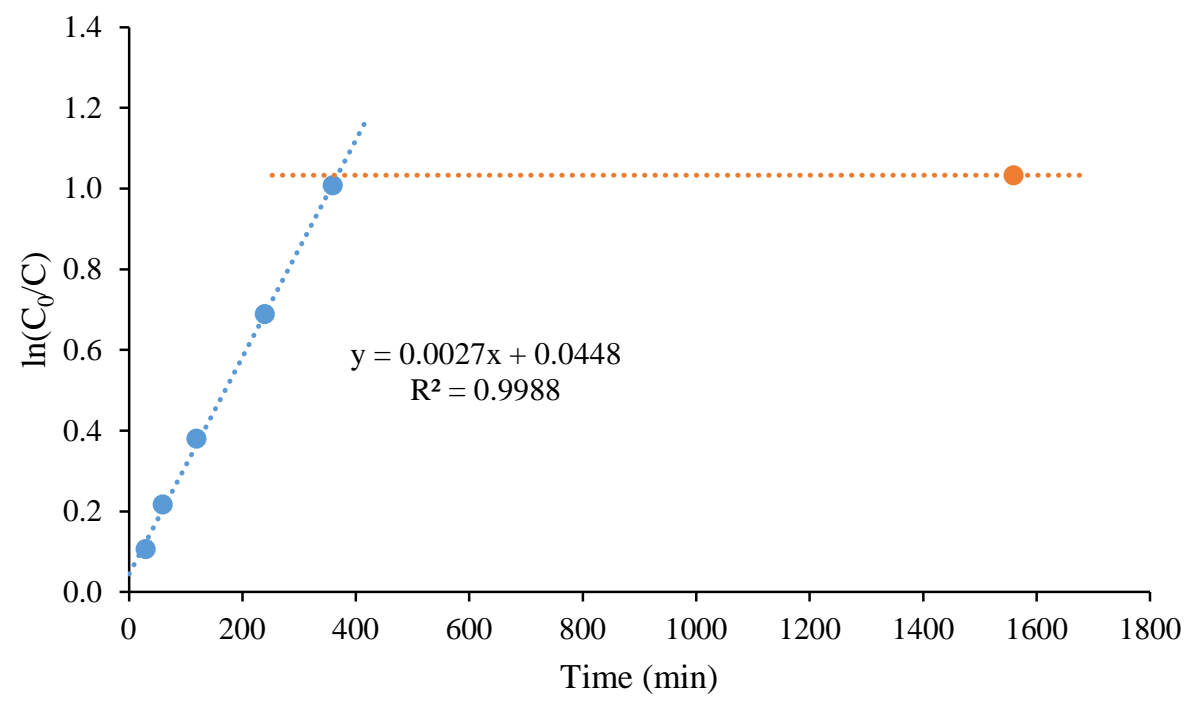


Figure S9. First order plot for the epoxide ring opening of styrene oxide with 2-propanol using catalyst III at ambient temperature $\left(23^{\circ} \mathrm{C}\right)$ before (blue) and after (orange horizontal) the filtration of the reaction mixture (Expt. 1).

Ve. Catalyst reusing experiment. A suspension of the catalyst III (20 mg, $0.2 \mathrm{~mol} \%$ ) in isopropyl alcohol (2.0 mL) was sonicated for $2 \mathrm{~min}$ and then stirred for 5 additional min at $60{ }^{\circ} \mathrm{C}$. Styrene oxide $(0.1 \mathrm{~mL})$ was added at $60^{\circ} \mathrm{C}$ and the reaction was followed by NMR as described in section Vb. After 22h no starting epoxide was detected and a new portion of styrene oxide $(0.1 \mathrm{~mL})$ was added. Immediate NMR analysis of the alcohol to epoxide ratio showed that $17 \%$ of the well-dispersed mixture was used for the aliquots. Thus, the kinetic parameters were multiplied by 1.06 to compensate for the catalyst to volume loss (Table S7b). Kinetic analysis (Figure S9b) showed that the catalyst lost 60\% of its activity after $22 \mathrm{~h}$ in the reaction mixture and 500 turn-overs.

Table S7b. Epoxide consumption as a function of time with catalyst III at $60^{\circ} \mathrm{C}$.

\begin{tabular}{|c|c|c|}
\hline Time (min) & Epoxide (\%) & $\ln \left(\mathrm{C}_{0} / \mathrm{C}\right)^{*}$ \\
\hline 10 & 75.8 & 0.277 \\
\hline 20 & 61 & 0.494 \\
\hline 30 & 52.9 & 0.637 \\
\hline 1320 & 0 & - \\
\hline 1320 & next portion added \\
\hline 0 & 100 & 0 \\
\hline 10 & 96.7 & 0.036 \\
\hline 20 & 85.6 & 0.165 \\
\hline
\end{tabular}




\begin{tabular}{|c|c|c|}
\hline 30 & 79.3 & 0.246 \\
\hline 62 & 66.4 & 0.434 \\
\hline
\end{tabular}

* Multiplied by 1.06 after second portion addition to compensate for the catalyst loss.

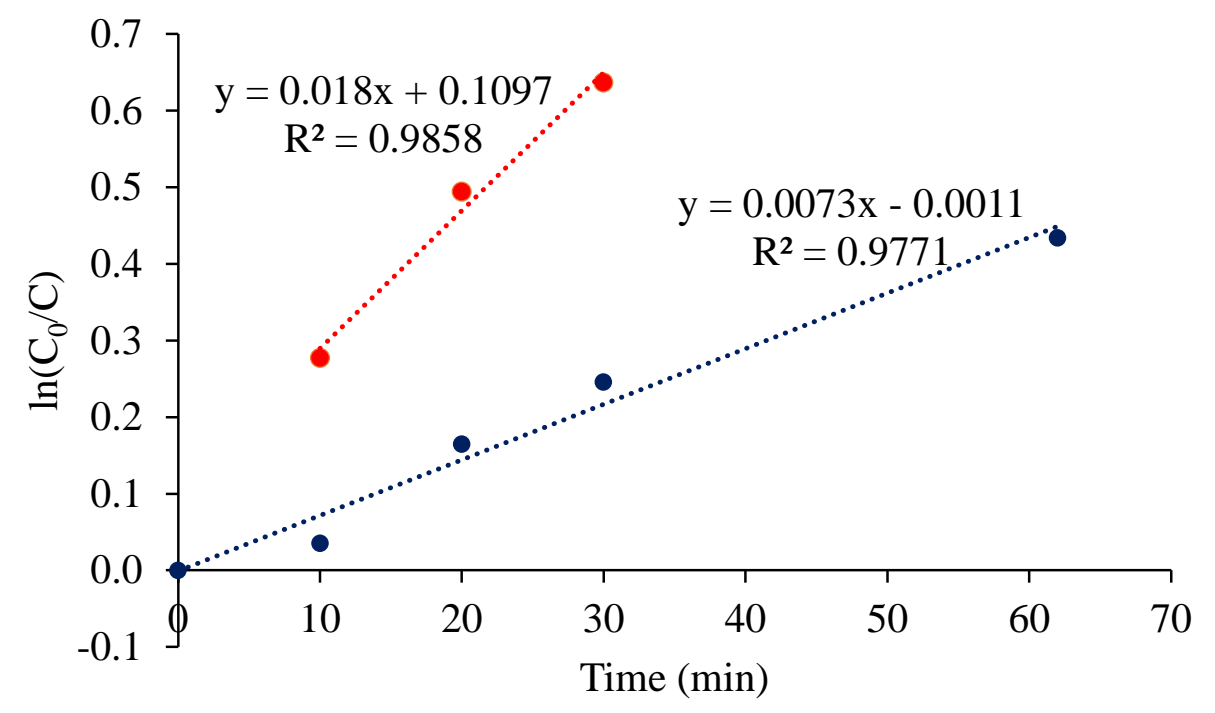

Figure S9b. First order plot for the epoxide ring opening of styrene oxide with 2propanol using catalyst III at $60^{\circ} \mathrm{C}$ (from Table S7b): first epoxide portion (red) reacted to completion before second portion added at 22h (blue). 


\section{Hydride transfer and acetalization reactions with and without pyridine.}

VIa. Effect of the polarity of the reaction solution.

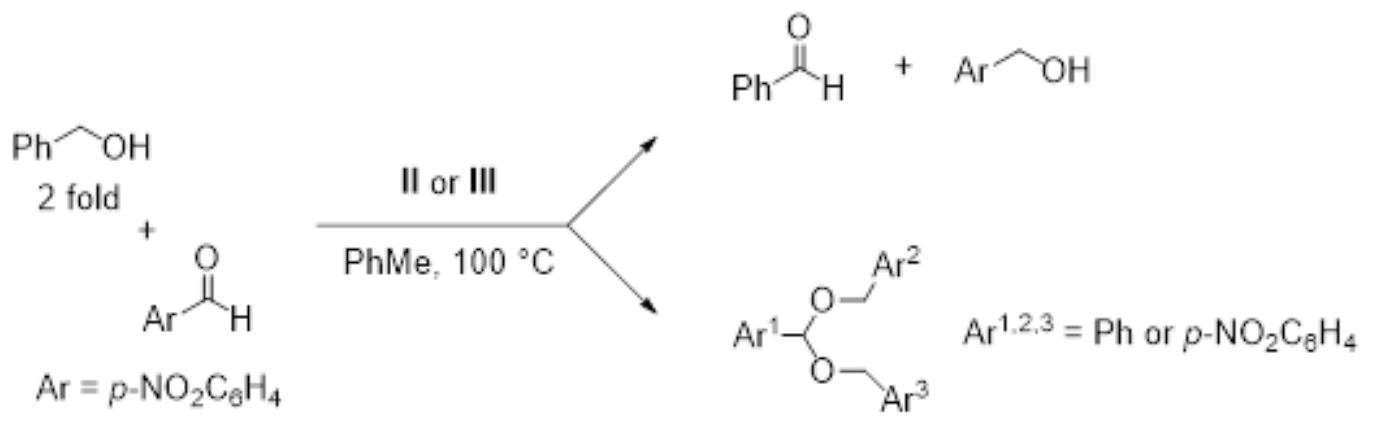

A mixture of catalyst (10 mg, $0.23 \mathrm{~mol} \%$ ), p-nitrobenzaldehyde (60 mg, $0.40 \mathrm{mmol}$ ), benzyl alcohol $(0.08 \mathrm{~mL}, 0.8 \mathrm{mmol})$ and dry toluene $(0.3 \mathrm{~mL})$ was heated at $100{ }^{\circ} \mathrm{C}$. A $50 \%$ conversion to the corresponding acetal was observed by ${ }^{1} \mathrm{H}$ NMR with III after $1 \mathrm{~h}$, whereas $\leq$ $1 \%$ of acetalization was observed in case of II even after $16 \mathrm{~h}$. Hydride transfer rate was similar for both catalysts with ca. 30-35\% hydride transfer products (p-nitrobenzyl alcohol and its acetals) after $16 \mathrm{~h}$. The reactions were also conducted with a larger excess of alcohol to aldehyde and in the absence of toluene to examine the effect of the polarity of the reaction medium on the product formation. 
Table S8. Effect of polarity of reaction medium on product yield in $p$-nitrobenzaldehyde reaction with benzyl alcohol over II and III.

\begin{tabular}{|c|c|c|c|c|c|}
\hline Alcohol/aldehyde/toluene & \multirow{2}{*}{ Time (h) } & \multicolumn{2}{|c|}{ II } & \multicolumn{2}{c|}{ III } \\
\cline { 3 - 6 } & & Acetals & H-transfer & Acetals & H-transfer \\
\hline $2 / 1 / 7$ & & & & & \\
\hline $2 / 1 / 7$ & 1 & $<1 \%$ & $<5 \%$ & $50 \%$ & $<5 \%$ \\
\hline $8 / 1 / 7$ & 16 & $\sim 25 \%$ & $\sim 78 \%$ & $\sim 72 \%$ & $\sim 30 \% *$ \\
\hline $8 / 1 / 0$ & 2.4 & $24 \%$ & $61 \%$ & - & - \\
\hline
\end{tabular}

* The reaction time for III under this condition was 19h. The H-transfer may appear to be small due to the high rate of acetal formation, but an examination of the two forms of aldehydes in the products indicated that the benzylaldehyde accounted for $72 \%$ of the aldehydes present.

\section{VIb. Effect of pyridine poisoning}

A mixture of catalyst $(10 \mathrm{mg})$, benzyl alcohol $(0.3 \mathrm{~mL}), p$-nitrophenyl benzaldehyde (51.7-55.5 $\mathrm{mg})$, dry toluene $(0.3 \mathrm{~mL})$ and pyridine additive was sonicated for 2 min and heated at $100{ }^{\circ} \mathrm{C}$. The reaction conversion and product yield were obtained by drawing aliquots at specific times and filtering them through celite in $\mathrm{CDCl}_{3}$. Pseudo-first order kinetics analysis was applied. No effect of pyridine additive or slight acceleration were observed for the hydride transfer process for grafted catalyst II, and slight deceleration was found for the calcined catalyst III. At the same time, the aldol formation was suppressed by pyridine (more than 30 fold reduction in rate). 
Table S9. Effect of pyridine on the reaction of p-nitrobenzaldehyde reaction with benzyl alcohol over II and III.

\begin{tabular}{|c|c|c|c|c|}
\hline Sample & $\begin{array}{c}\text { Pyridine } \\
(\mu \mathrm{L})\end{array}$ & $\mathrm{Py} / \mathrm{Sn}$ & $\begin{array}{c}\text { Hydride transfer } \\
\mathrm{k}_{\mathrm{h}} \mathrm{X} 0^{3}\left(\mathrm{~min}^{-1}\right)\end{array}$ & activity \\
\hline II & 0 & 0 & 1.6 & 100 \\
\hline II & 0.02 & 0.30 & 1.7 & 100 \\
\hline II & 0.2 & 3 & $\sim 3.8$ & 200 \\
\hline II & 10 & 150 & 2.6 & 160 \\
\hline III & 0.0 & 0 & 0.5 & 100 \\
\hline III & 10 & 150 & 0.32 & 64 \\
\hline
\end{tabular}

VII. Reactions in the presence of water: epoxide ring opening with water<smiles>OCC(O)c1ccccc1</smiles>

To a suspension of III (10 mg, $0.105 \mathrm{~mol} \%)$ in water $(0.25 \mathrm{~mL})$ was added styrene oxide (0.1 $\mathrm{mL}$ ) and the mixture was stirred for $2 \mathrm{~h}$ at $50^{\circ} \mathrm{C} . \mathrm{CDCl}_{3}(1.0 \mathrm{~mL})$ with diphenyl methane (25 $\mu \mathrm{L}$ ) as an internal standard were added, and ${ }^{1} \mathrm{H}$ NMR indicated $94 \%$ conversion and $56 \%$ yield of the glycol product. When the reaction was carried out at room temperature, $2 \%$ yield was observed after $10 \mathrm{~min}$, and $21 \%$ after $2 \mathrm{~h}$. 


\section{Glucose reaction}

$\gamma$-valerolactone $(0.5 \mathrm{~mL})$ was added to glucose $(43.2 \mathrm{mg}, 240 \mu \mathrm{mol})$ and calcined catalyst III (10 mg, $0.4 \mathrm{~mol} \%$ ) and the mixture was heated at $200^{\circ} \mathrm{C}$ in a nitrogen flushed vial for $1 \mathrm{~h}$.

Deuterium oxide $(1.0 \mathrm{~mL})$ was added. ${ }^{13} \mathrm{C}$ NMR analysis indicated complete conversion and these products with approximate yields: fructose (25\%), 1-furfural (5\%), 5(hydroxymethyl)furfural (5\%).

Glucose reaction was also conducted with a catalyst (III') synthesized with a homolog of I in which the R-group was $i$-butyl instead of $c$-hexyl. After calcination, the EXAFs data showed III' was more disordered than III with an average Sn coordination $=4.7 \pm 0.4$. Preliminary data showed that this catalyst also catalyzed glucose reaction in an Ace pressure tube. $1 \mathrm{~g}$ of glucose was dissolved in water and ethanol ( $\mathrm{V} / \mathrm{V}=50: 50)$ to form $10 \mathrm{wt} \%$ solution. The molar ratio of Sn/glucose is $1 / 100$. Reaction took place at $140^{\circ} \mathrm{C}$ with $750 \mathrm{rpm}$ stirring and terminated after 2h. The products were analyzed with Agilent 1200 HPLC, using Carbosep Corgel-87C column (Transgenomic) at $85^{\circ} \mathrm{C}$ with ultra pure HPLC grade water as the mobile phase. 
Table S10. Glucose reaction catalyze d by III' in water ethanol mixture $(50: 50 \mathrm{v} / \mathrm{v})$ at $140{ }^{\circ} \mathrm{C}$

\begin{tabular}{|c|c|c|c|c|c|c|c|c|c|}
\hline \multirow{2}{*}{ Solvent } & \multirow{2}{*}{$\begin{array}{c}\text { Conv. } \\
\%\end{array}$} & \multicolumn{8}{|c|}{ Selectivity\% } \\
\hline & & Disaccharide & $\begin{array}{l}\text { Ethyl } \\
\text { glucoside }\end{array}$ & mannose & unknown & fructose & $\begin{array}{l}\text { Soluble } \\
\text { humins }\end{array}$ & HMF & humins \\
\hline $\mathrm{H}_{2} \mathrm{O}:$ & & & & & & & & & \\
\hline $\begin{array}{l}\mathrm{C}_{2} \mathrm{H}_{5} \mathrm{OH} \\
(50: 50 \mathrm{v} / \mathrm{v})\end{array}$ & 25.2 & 17.3 & 38.1 & 3.1 & 5.1 & 14.0 & 3.0 & 4.0 & 15.4 \\
\hline $\mathrm{H}_{2} \mathrm{O}$ & 8.8 & 59.1 & 0 & 7.8 & 0 & 11.5 & 12.1 & 9.3 & 0.2 \\
\hline
\end{tabular}

\section{Cellobiose conversion}

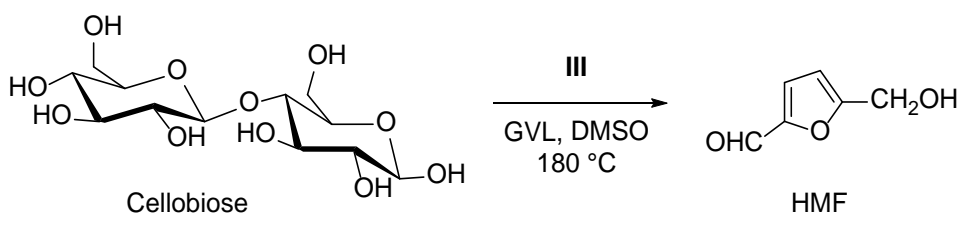

To a mixture of cellobiose (39.2 mg, $115 \mu \mathrm{mol})$ and calcined catalyst III (10 mg, $0.8 \mathrm{~mol} \%$ ) was added $\gamma$-valerolactone $(0.3 \mathrm{~mL})$ and DMSO- $d_{6}(0.1 \mathrm{~mL})$. The mixture was sonicated for $2 \mathrm{~min}$, and heated at $180{ }^{\circ} \mathrm{C}$ for $2.2 \mathrm{~h}$ in a nitrogen flushed vial. ${ }^{1} \mathrm{H}$ NMR with dichloromethane as an internal standard indicated full conversion and $30 \%$ yield of 5-(hydroxymethyl)furfural. ${ }^{13} \mathrm{C}$ NMR analysis showed no detectable products $(<5 \%)$ when cellobiose was heated under the same conditions without III. 
